\title{
Urticaria from penicillin as the sole clue to acute onset of disabling arthritis
}

\section{Brittany Urso', James A. Solomon ${ }^{1,2,3}$}

${ }^{1}$ University of Central Florida College of Medicine, Orlando Florida, USA, ${ }^{2}$ University of Illinois College of Medicine, Urbana Illinois, USA, ${ }^{3}$ Ameriderm Research, Ormond Beach Florida, USA

Corresponding author: Brittany Urso, E-mail: Brittany.Urso@knights.ucf.edu

Sir,

Many patients suffer from diseases of unknown cause, while the cause surrounds them disguised by deceptive labelling terms. Patients with rashes from fragrances will continue to suffer despite using "unscented" skin products and soaps which contain fragrances under the label of "essential oils". They may react also to natural food/plant sources of the fragrance. Cinnamic aldehyde, a common contact allergen derived from cinnamon, and Balsam of Peru are used to make fragrances for perfumes, skin products, and tobacco. Despite $70 \%$ of drugs being food/plant derivatives, the natural source of a drug is often overlooked as clinically important in assessing "drug" allergens [1].

\section{Report of a Case}

We present a healthy 35-year-old nurse with a history of urticaria from penicillin who suddenly developed polyarthralgias over a 3-month period. Since she could no longer jog, nor even climb one flight of stairs and had failed to respond to medications, she planned to take a medical leave of absence and move onto the first floor of her house. She had been seen by several rheumatologists who, after an extensive workup with blood tests and radiology exam, were unable to identify the etiology of this acute arthritis nor to find a medication which controlled her symptoms. She was emphatic that she had not taken any penicillin, nor related medications, prior to the onset of this event. She denied any hypersensitivities or significant changes in her lifestyle, exposures, or diet associated with this period aside from her family hosting a French exchange student for the last 4-months. After discussing the patient's penicillin allergy with her, as well as the way penicillin was discovered, it was mentioned that penicillin is a common contaminant of any aging naturally rotting substance [2]. With this, she realized a potential source of her arthritis. To lessen the exchange student's homesickness, she purchased aged cheeses for everyone to eat after school. With the acknowledgement that cheese is a natural source of penicillin, she changed her diet and within 2 weeks her polyarthralgias resolved [2].

\section{DISCUSSION}

The goal of this paper is to reinforce the idea that, especially in patients with atypical treatment resistant disease, there may be a hidden etiology which triggers the patient's condition. The clue to such may include a history of an adverse cutaneous reaction. Although it is well recognized that many medications are derived from plant, animal, or mineral natural sources, what may not be considered is that reaction to medications also may indicate reactions to the food sources of these medications [3]. These reactions to the natural sources of medications may be more likely in patients who have had severe reactions to the medication, suggesting that a molar exposure lower than required for therapeutic effect can elicit an adverse immune response [4].

\section{REFERENCES}

1. Kiec-Swierczynska M, Krecisz B, Swierczynska-Machura D. [Contact allergy to fragrances]. Med Pr. 2006;57:431-7.

2. Laich F, Fierro F, Martin JF. Production of penicillin by fungi growing on food products: identification of a complete penicillin gene cluster in Penicillium griseofulvum and a truncated cluster in Penicillium verrucosum. Appl Environ Microbiol. 2002;68:1211-9. 
www.odermatol.com

3. Zeng ZP, Jiang JG. Analysis of the adverse reactions induced by natural product-derived drugs. Br J Pharmacol. 2010;159:1374-91.

4. Aronson JK, Ferner RE. The law of mass action and the pharmacological concentration-effect curve: resolving the paradox of apparently non-dose-related adverse drug reactions. Br J Clin Pharmacol. 2016;81:56-61.
Copyright by Brittany Urso, et al. This is an open-access article distributed under the terms of the Creative Commons Attribution License, which permits unrestricted use, distribution, and reproduction in any medium, provided the original author and source are credited.

Source of Support: Nil, Conflict of Interest: None declared. 